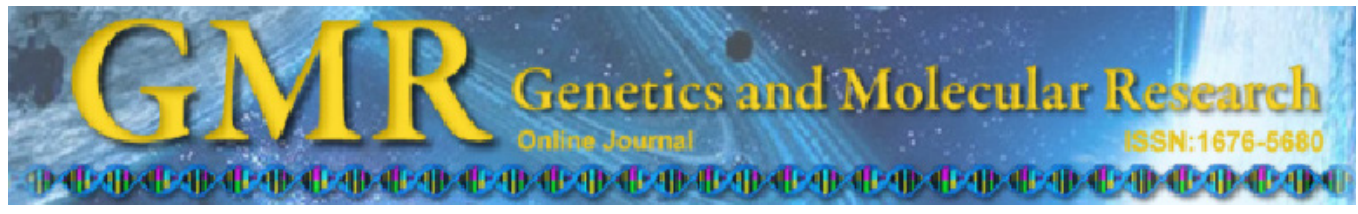

\title{
Expression and purification of GST-FHL2 fusion protein
}

\author{
H. Yu, Q. Ma, J. Lin, Y.F. Sun and F. Zheng \\ Department of Cardiology, Guangdong General Hospital, \\ Guangdong Provincial Cardiovascular Institute, \\ Guangdong Academy of Medical Sciences, Guangzhou, China \\ Corresponding author: J. Lin \\ E-mail: linjijin@yahoo.com.cn
}

Genet. Mol. Res. 12 (4): 6372-6378 (2013)

Received November 30, 2012

Accepted May 15, 2013

Published December 6, 2013

DOI http://dx.doi.org/10.4238/2013.December.6.4

\begin{abstract}
Escherichia coli is the most widely used host for the production of recombinant proteins. However, most eukaryotic proteins are typically obtained as insoluble, misfolded inclusion bodies that need solubilization and refolding. The interactions between human FHL2 protein and many types of proteins, including structural proteins, kinases, and several classes of transcription factor, have been found to have important roles in a variety of fundamental processes, including arrhythmia, hypertrophy, atherosclerosis, and angiogenesis. To achieve high-level expression of soluble recombinant human FHL2 protein in E. coli, we have constructed a recombinant expression plasmid, pGEX-4T-1-FHL2, in which we merged FHL2 cDNA with the glutathione S-transferase (GST) coding sequence downstream of the tac inducible promoter. Using this plasmid, we have achieved high expression of soluble FHL2 as a GST fusion protein in $E$. coli BL21. We have used the engineered plasmid (pGEX-4T-1-FHL2) and the modified E. coli strain to overcome the problem of removing the GST moiety while expressing soluble FHL2. Our results show that: 1) the recombinant plasmid was successfully constructed. Sequencing results showed that FHL2 and GST are in the same reading frame; 2) at $23^{\circ} \mathrm{C}$, soluble GST-FHL2 fusion protein was highly expressed after induction
\end{abstract}


with $0.1 \mathrm{mM}$ IPTG; and 3) GST-FHL2 can be detected by Western blotting using mouse monoclonal anti-GST antibody. Our data are the first to show that high yields of soluble FHL2 tagged with GST can be achieved in E.coli.

Key words: FHL2; GST; Fusion protein; Prokaryotic expression; Protein purification

\section{INTRODUCTION}

FHL (four and a half LIM domains) protein consists of four complete and one half LIM domain, and belongs to a family that in humans includes FHL1, FHL2, FHL3, FHL4 and ACT (Chan et al., 1998; Johannessen et al., 2006). FHL4 and ACT are expressed in the testis (Fimia et al., 1999; Morgan and Madgwick, 1999a), FHL1 and FHL3 are expressed at relatively high levels in skeletal muscle, and FHL2 is expressed at high levels in the heart and at low levels in skeletal muscle (Morgan and Madgwick, 1999b). The LIM domain is a multifunctional protein/protein interaction domain of approximately 50-60 amino acids. Each cysteine-rich LIM domain binds two zinc ions to form a finger-like structure (Kosa et al., 1994; Dawid et al., 1998). Approximately 50 different proteins have been described so far that specifically interact with FHL2. The majority of these proteins show little or no sequence or structural homology, and participate in a wide variety of cellular processes. Many of these proteins are components of signaling pathways (receptors, receptor-interacting proteins, protein kinases, transcription factors, and cofactors) that regulate, e.g., cell proliferation, apoptosis, and gene expression. FHL2 protein can also act as a transcriptional cofactor: it has the intrinsic properties of transcriptional activation and common transcriptional inhibition, and it crucially functions in cell cycle regulation, cell apoptosis, cell cytoskeleton formation, and signal transduction (Johannessen et al., 2006). These interactions have important roles in a variety of fundamental processes, including arrhythmia, hypertrophy, atherosclerosis, and angiogenesis (Chu and Chen, 2011). The availability of high yields of high purity FHL2 protein would be very helpful in studies of FHL2 function. This report is therefore mainly about how high level production of soluble and functional GST-tagged FHL2 can be achieved in Escherichia coli.

\section{MATERIAL AND METHODS}

\section{Materials}

JM109, BL21(DE3) competent cells, Taq polymerase, restriction enzymes (EcoRI, XhoI), and ligation mix were bought from TaKaRa Biotechnology Co., Ltd. (Dalian, China). The prokaryotic expression vector pGEX-4T-1 was bought from Amersham Pharmacia Biotech Inc. (USA). Primer synthesis and recombinant plasmid sequencing was completed by TaKaRa Biotechnology Co., Ltd. (Dalian, China). High-affinity GST Resin was bought from GenScript Co., Ltd. (Nanjing, China). Phenylmethylsulfonyl fluoride (PMSF) was bought from SigmaAldrich (USA). Prestained protein ladder was bought from Fermentas Inc (USA). Mouse antiGST monoclonal antibody was bought from Applygen Technologies Inc. (Beijing, China). The goat-anti-mouse secondary antibody conjugated with horseradish peroxidase (HRP) was bought from Abcam (USA). ECL Western blotting substrate was bought from Thermo Scientific (USA). 


\section{Construction of recombinant plasmid pGEX-4T-1-FHL2}

Using full-length FHL2 cDNA as a template for polymerase chain reaction (PCR) amplification, an FHL2 protein coding fragment was produced with EcoRI and XhoI restriction enzyme cut sites at the $5^{\prime}$ and $3^{\prime}$ termini, respectively. The upstream primer sequence was 5'-GCATGAATTCATGACTGAGCGCTTTGACT-3' (with an EcoRI enzyme cut site), and the downstream primer sequence was 5'-TTATCTCGAGTCAGATGTCTTTCCCACAGT-3' (with an $\mathrm{XhoI}$ enzyme cut site). PCR amplification conditions: Initial denaturation was at $94^{\circ} \mathrm{C}$ for $4 \mathrm{~min}$, followed by 30 cycles of denaturation at $94^{\circ} \mathrm{C}$ for $1 \mathrm{~min}$, annealing at $59^{\circ} \mathrm{C}$ for 1 min, and extension at $72^{\circ} \mathrm{C}$ for $80 \mathrm{~s}$. The final extension was at $72^{\circ} \mathrm{C}$ for $10 \mathrm{~min}$. The FHL2 gene PCR product and the expression vector pGEX-4T-1 were cut with EcoRI and XhoI enzymes and then ligated together to make the recombinant plasmid pGEX-4T-1-FHL2.

\section{Induction and expression of the GST-FHL2 fusion protein}

Two hundred and fifty-microliter culture of BL21 E. coli transformed with pGEX-4T1-FHL2 recombinant plasmid was added into $500 \mathrm{~mL}$ LB containing $100 \mu \mathrm{g} / \mathrm{mL}$ ampicillin and then incubated at $37^{\circ} \mathrm{C}$ with shaking at $250 \mathrm{rpm}$. The $\mathrm{OD}_{600}$ was checked periodically until it reached 0.5-0.6. One milliliter of the culture was set aside as an uninduced control. The culture was induced with IPTG under a range of conditions: 1) induction at $37^{\circ} \mathrm{C}$ for $5 \mathrm{~h}$ with $0.1 \mathrm{mM}$, $0.4 \mathrm{mM}$, or $0.8 \mathrm{mM}$ IPTG; 2) induction at $30^{\circ} \mathrm{C}$ for $5 \mathrm{~h}$ with $0.1 \mathrm{mM}, 0.4 \mathrm{mM}$, or $0.8 \mathrm{mM}$ IPTG; 3) induction at $23^{\circ} \mathrm{C}$ for $5 \mathrm{~h}, 7 \mathrm{~h}$, or $9 \mathrm{~h}$ with $0.1 \mathrm{mM}$ IPTG. Cells were harvested by centrifugation at $3000 \mathrm{~g}$ and $4^{\circ} \mathrm{C}$ for $10 \mathrm{~min}$, the supernatants discarded, and the cell pellets resuspended in $3 \mathrm{~mL}$ ice-cold phosphate-buffered saline buffer (PBS) before a second centrifugation at 3000 $g$ and $4^{\circ} \mathrm{C}$ for $10 \mathrm{~min}$. The supernatants were discarded and the cell pellets frozen at $-80^{\circ} \mathrm{C}$ overnight. The next day, the cell pellets were thawed on ice and the cells re-suspended in 3 $\mathrm{ml}$ ice-cold PBS. One millimolar protease inhibitor (PMSF) was added. Cells were broken by brief sonication pulses on ice until the samples were no longer viscous. (Sonication conditions: ultrasonic power, $400 \mathrm{~W}$; ultrasonicate 80 times in $10 \mathrm{~s}$ bursts interspersed with $10 \mathrm{~s}$ pauses). The sonicates were centrifuged at $6000 \mathrm{~g}$ and $4^{\circ} \mathrm{C}$ for $15 \mathrm{~min}$, and the supernatants (soluble fraction) carefully transferred to a clean, pre-chilled tube. The pellets (insoluble fraction) were resuspended in $3 \mathrm{~mL}$ ice-cold PBS per $50 \mathrm{~mL}$ of initial E. coli culture. As a control in this experiment, the pGEX-4T-1 vector with no FHL2 insert was transferred to BL21(DE3) and treated under the same conditions as those for expression of GST-FHL2.

\section{Purification of the GST-FHL2 fusion protein}

High affinity GST agarose resin was used for purification of the GST-FHL2 fusion protein and the soluble GST protein (supernatant). The bottle containing the high affinity GST Resin was gently shaken until all the resin was completely in suspension. six milliliters of resin suspension (50\% slurry) was transferred to a disposable column and washed with 10 bed volumes of cold $\left(4^{\circ} \mathrm{C}\right)$ PBS. PBS sonicate containing either the GST-fusion protein or GST was applied to the equilibrated column with a flow rate of $15 \mathrm{~cm} / \mathrm{h}$. The column was washed with 20 bed volumes of PBS immediately after all the protein solution had entered. It is advisable to add protease inhibitors such as PMSF to the wash solution. The fusion protein was 
eluted with 10-15 bed volumes of freshly made $10 \mathrm{mM}$ glutathione elution buffer. Elution was monitored by measuring absorbance at $280 \mathrm{~nm}$. Ten to twenty-microliter aliquots of supernatant containing GST or GST-fusion protein, flow through, wash, and the eluted protein were analyzed by SDS-PAGE to confirm the presence of the proteins of interest.

\section{Western blot analysis of GST-FHL2 fusion protein}

After separating the purified GST-FHL2 fusion protein and GST protein by $15 \%$ SDSPAGE at $200 \mathrm{~mA}$ constant current for $2 \mathrm{~h}$, the recombinant protein was transferred to cellulose nitrate film (NC membrane). The NC membrane was blocked for $1 \mathrm{~h}$ at room temperature with $50 \mathrm{~g} / \mathrm{L}$ skimmed milk, then treated with mouse anti-GST antibody diluted 1:300, kept at room temperature for $30 \mathrm{~min}$, then at $4^{\circ} \mathrm{C}$ overnight. Next day, the membrane was washed 3 times for 5 min with Tris buffered saline ( $50 \mathrm{mM}$ Tris-Cl, $\mathrm{pH} 7.6 ; 150 \mathrm{mM} \mathrm{NaCl})$ solution, and then treated for $1 \mathrm{~h}$ at $37^{\circ} \mathrm{C}$ with the secondary antibody (goat-anti-mouse conjugated with HRP) diluted 1:3000. The membrane was washed 3 times with TBS, $10 \mathrm{~min} /$ wash, and finally treated for chemiluminescence development.

\section{RESULTS}

\section{Identification of recombinant plasmid pGEX-4T-1-FHL2}

Recombinant plasmid pGEX4T-1-FHL2 was cut with both EcoRI and XhoI enzymes and the products analyzed by electrophoresis on a $10 \mathrm{~g} / \mathrm{L}$ agarose gel. Results are shown in Figure 1. The recombinant plasmid was cut into two fragments by the enzymes, one corresponding to the vector, and the second to the inserted FLH2 DNA. The recombinant plasmid was sent to Dalian TaKaRa company for sequencing. The result confirmed that the recombinant plasmid sequences were as designed, with the FHL2 coding fragment in the same reading frame as GST (Figure 2).

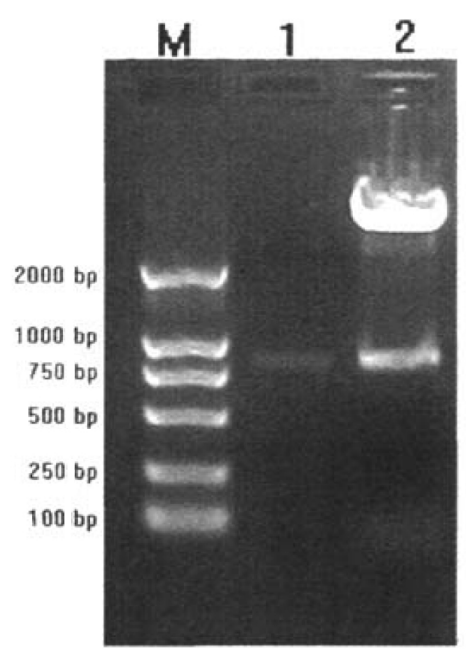

Figure 1. Recombinant plasmid pGEX-4T-1/FHL2 enzyme cut identification. Lane $M=$ DNA marker DL2000; lane 1 = FHL2 gene PCR products; lane 2 = pGEX-4T-1/FHL2/EcoRI/XhoI. 


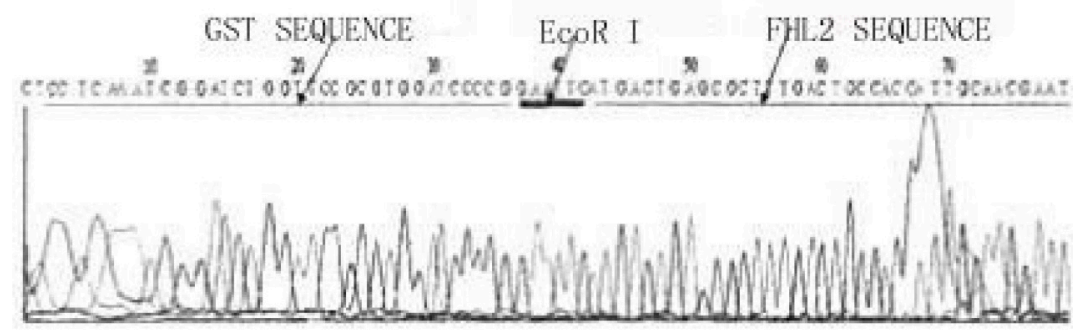

Figure 2. Recombinant plasmid pGEX-4T-1/FHL2 sequencing diagram.

\section{Induction of GST-FHL2 fusion protein expression}

We found that at $37^{\circ}$ and $30^{\circ} \mathrm{C}$, all of the IPTG concentrations tested $(0.1,0.4,0.8 \mathrm{mM})$ efficiently induced GST-FHL2 expression, but most of the product expressed was in the form of inclusion bodies. Induction with $0.1 \mathrm{mM} \mathrm{IPTG}$ at $23^{\circ} \mathrm{C}$ for $9 \mathrm{~h}$, however, also efficiently expressed GST-FHL2, but with about $50 \%$ of the expressed protein being in a soluble form. SDSPAGE analysis showed that all the GST-FHL2 fusion proteins banded in the same position, and we obtained a protein band of approximately $26 \mathrm{kDa}$, corresponding to the size of GST (Figure 3).

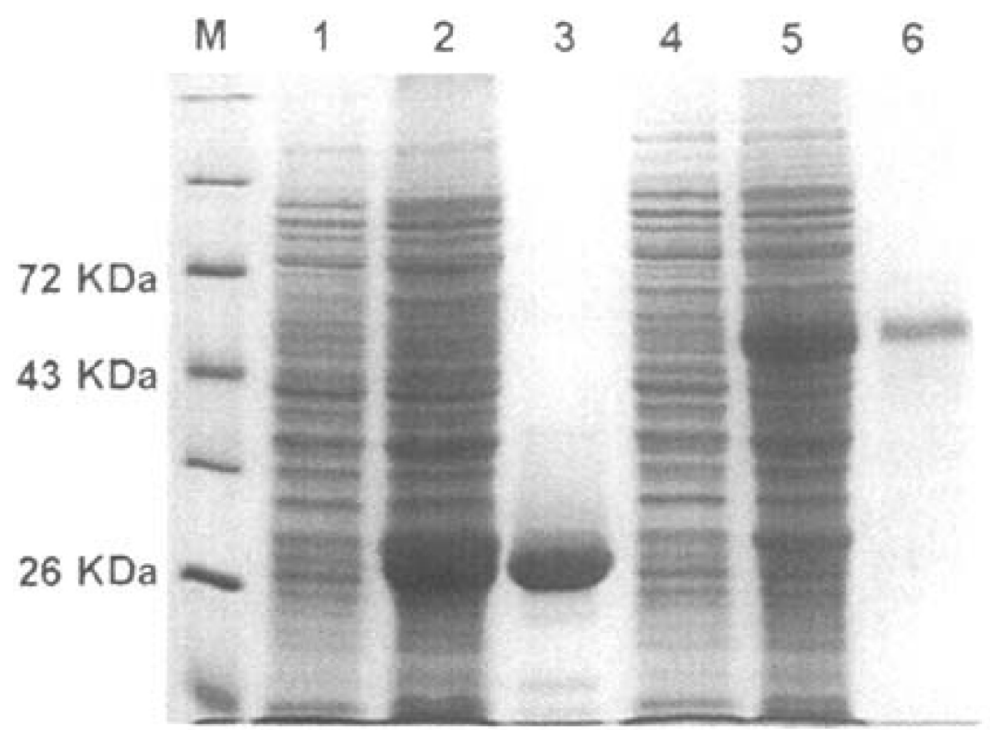

Figure 3. SDS-PAGE analysis of fusion protein expression and purification of GST-FHL $2\left(23^{\circ} \mathrm{C}\right)$. Lane $M=$ protein marker; lane $1=\mathrm{GST}$ before induction; lane $2=\mathrm{GST}$ after induction; lane $3=\mathrm{GST}$ after purification; lane $4=$ GST-FHL2 before induction; lane $5=$ GST-FHL2 after induction; lane $6=$ GST-FHL2 after purification.

\section{Western blot analysis of purified GST-FHL2 protein}

The SDS-PAGE separations of GST-FHL2 fusion protein and GST protein were trans- 
ferred to NC membrane for Western blot analysis as described above. The results showed that the purified protein bands bound anti-GST antibody, proving that the purified proteins are GST and the GST fusion protein (Figure 4).

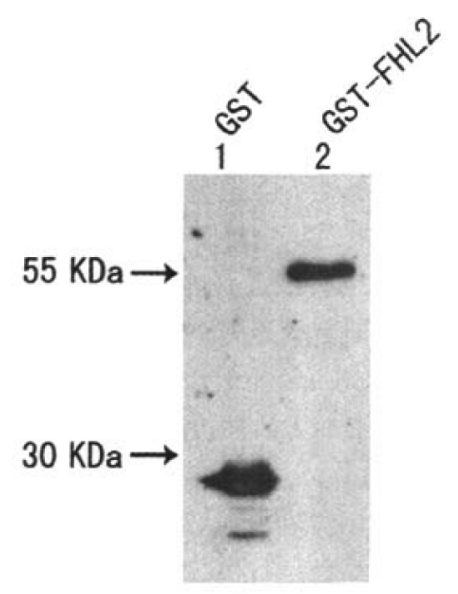

Figure 4. Western blot analysis of purified GST and GST-FHL2 fusion protein. Lane $1=$ GST protein; lane $2=$ GST-FHL2 fusion protein.

\section{DISCUSSION}

In this study, we successfully constructed the pGEX-4T-1-FHL2 recombinant plasmid and introduced it into E. coli BL21, where it expressed the GST-FHL2 fusion protein when induced with IPTG. Because FHL2 protein is rich in cysteine residues, the recombinant fusion protein has many sulfur-containing amino acids. In the folding process, it is easy for such a protein to form inclusion bodies. However, it is necessary to achieve soluble expression of the fusion protein. To solve this problem, we first induced expression of the fusion protein at higher culture temperatures $\left(37^{\circ}\right.$ and $\left.30^{\circ} \mathrm{C}\right)$ and found that most of the expressed fusion protein was in the form of inclusion bodies. The high speed of protein synthesis at these temperatures makes fusion body formation likely to occur. We reasoned by lowering the temperature (Rabhi-Essafi et al., 2007) it would slow the rate of protein synthesis and promote correct protein folding over the formation of inclusion bodies, thereby increasing soluble protein expression. Therefore, we decreased the induction temperature to $23^{\circ} \mathrm{C}$, and extended the induction time, so that the foreign protein could express sufficiently. The results showed that at the lower temperature conditions, soluble protein expression quantity increased significantly. We also added PMSF during the protein extraction and purification process to reduce degradation of the fusion protein. We thus gained soluble expression of the fusion protein.

In addition, it is necessary that the experimental procedures ensure that the fusion protein retains its biological activity through purification with high-affinity GST resin and elution with glutathione. The process and methods of this study on the prokaryotic expression of a fusion protein have a certain reference value, while at the same time the research successfully expressed the GST-FHL2 fusion protein. The purified protein can be used for further experimental study. 


\section{ACKNOWLEDGMENTS}

Research supported by the National Natural Science Foundation of China (\#81070151), and the Natural Science Foundation of Guangdong Province, China (project\#S2012010009324).

\section{REFERENCES}

Chan KK, Tsui SK, Lee SM, Luk SC, et al. (1998). Molecular cloning and characterization of FHL2, a novel LIM domain protein preferentially expressed in human heart. Gene 210: 345-350.

Chu PH and Chen J (2011). The novel roles of four and a half LIM proteins 1 and 2 in the cardiovascular system. Chang Gung. Med. J. 34: 127-134.

Dawid IB, Breen JJ and Toyama R (1998). LIM domains: multiple roles as adapters and functional modifiers in protein interactions. Trends Genet. 14: 156-162.

Fimia GM, De Cesare D and Sassone-Corsi P (1999). CBP-independent activation of CREM and CREB by the LIM-only protein ACT. Nature 398: 165-169.

Johannessen M, Moller S, Hansen T, Moens U, et al. (2006). The multifunctional roles of the four-and-a-half-LIM only protein FHL2. Cell Mol. Life Sci. 63: 268-284.

Kosa JL, Michelsen JW, Louis HA, Olsen JI, et al. (1994). Common metal ion coordination in LIM domain proteins. Biochemistry 33: 468-477.

Morgan MJ and Madgwick AJ (1999a). The fourth member of the FHL family of LIM proteins is expressed exclusively in the testis. Biochem. Biophys. Res. Commun. 255: 251-255.

Morgan MJ and Madgwick AJ (1999b). The LIM proteins FHL1 and FHL3 are expressed differently in skeletal muscle. Biochem. Biophys. Res. Commun. 255: 245-250.

Rabhi-Essafi I, Sadok A, Khalaf N and Fathallah DM (2007). A strategy for high-level expression of soluble and functional human interferon alpha as a GST-fusion protein in E. coli. Protein Eng. Des. Sel. 20: 201-209. 